\title{
THE SINUS VENOSUS TYPE OF INTERATRIAL SEPTAL DEFECT*
}

\author{
BY \\ H. R. S. HARLEY \\ Cardiff
}

(RECEIVED FOR PUBLICATION DECEMBER 30, 1957)

Defects of the interatrial septum, other than valvular patency of the foramen ovale, are often classified into ostium primum and ostium secundum varieties. The relationship of the former type to abnormal development of the atrioventricular canal has been stressed by several workers, including Rogers and Edwards (1948), Wakai and Edwards (1956), Wakai, Swan, and Wood (1956), Brandenburg and DuShane (1956), ToscanoBarbosa, Brandenburg, and Burchell (1956), and Cooley and Kirklin (1956). These workers prefer the term "persistent common atrioventricular canal " to " persistent ostium primum."

In addition to the above types of interatrial septal defect there is a third variety, which was described as long ago as 1868 by Wagstaffe, but which has come into prominence only since the introduction of surgical repair of interatrial communications under direct vision. This defect is called "high" by Lewis et al. (1955), "superior marginal " by Watkins and Gross (1955), " a defect associated with abnormal development of the pulmonary veins" by Hudson (1955), " the sinus venosus type" by Ross (1956), and "the superior-caval defect" by Bedford, Sellors, Somerville, Belcher, and Besterman (1957). I shall employ both the first of these terms, because it is short and is anatomically descriptive, and the last, because I believe the defect to be associated with an error of development of the sinus venosus, but not of the nature postulated either by Hudson (1955) or by Ross (1956).

An excellent anatomical description of this variety of interatrial communication has been given by Lewis et al. (1955), who found it to be at least as common as the ostium primum type of defect. The defect occurs high in the dorsicephalic part of the interatrial septum, facing the orifice of the superior vena cava, and has, according to Lewis et al., three anatomical characteristics,

\footnotetext{
*Arris a nd Gale Lecture deliver ed at the Royal College of Surgeons
} of England on Novembər 28, 1957. namely, (1) it lies above and independent of $\overrightarrow{\vec{N}}$ the fossa ovalis; (2) its margin is incomplete, being absent superiorly and incomplete posteriorly; and (3) it is associated with anomalous drainage of the right superior, and sometimes of the right middle or inferior, pulmonary vein. This type of defect is illustrated in Fig. 1 (after Lewis et al., 1955) and Fig. 2 (after Geddes, 1912). In the case reported by Ross (1956), who kindly permitted me to see the heart, the interatrial communication was described as “... lying within the orifice of the superior vena cava in its medial wall opposite the mouths of the anomalous pulmonary veins." Ross goes on to say: "On casual inspection of the interior of the left atrium. the defect was not visible unless a search was made within the superior caval orifice." The relationship of the defect to the orifice of the superior vena cava has led some authors, including Geddes (1912) and Ingalls (1907), to describe the anomaly as an abnormal entry of the superior vena cava rather than as an error in development of the interatrial septum. That the defect under consideration is above and independent of the foramen ovale (by which I mean the normal gap circumscribed by the septum secundum) is well shown in Fig. 1, which illustrates the ordinary variety of persistent ostium secundum, lying within the confines of a well-marked foramen ovale, as well as a high defect above the foramen ovale.

With regard to the surgical repair of abnorma interatrial communications, the sinus venosus type of defect is important for two reasons. The first is that it may be overlooked completely at the time of operation, and the second is that the anomalous pulmonary vein or veins may not be recognized, and after repair may be directed into the right instead of into the left atrium.

It is my purpose to determine how the sinus venosus type of interatrial septal defect occurs. No satisfactory explanation has yet been given. Lewis et al. (1955) point out that the defect occurs 


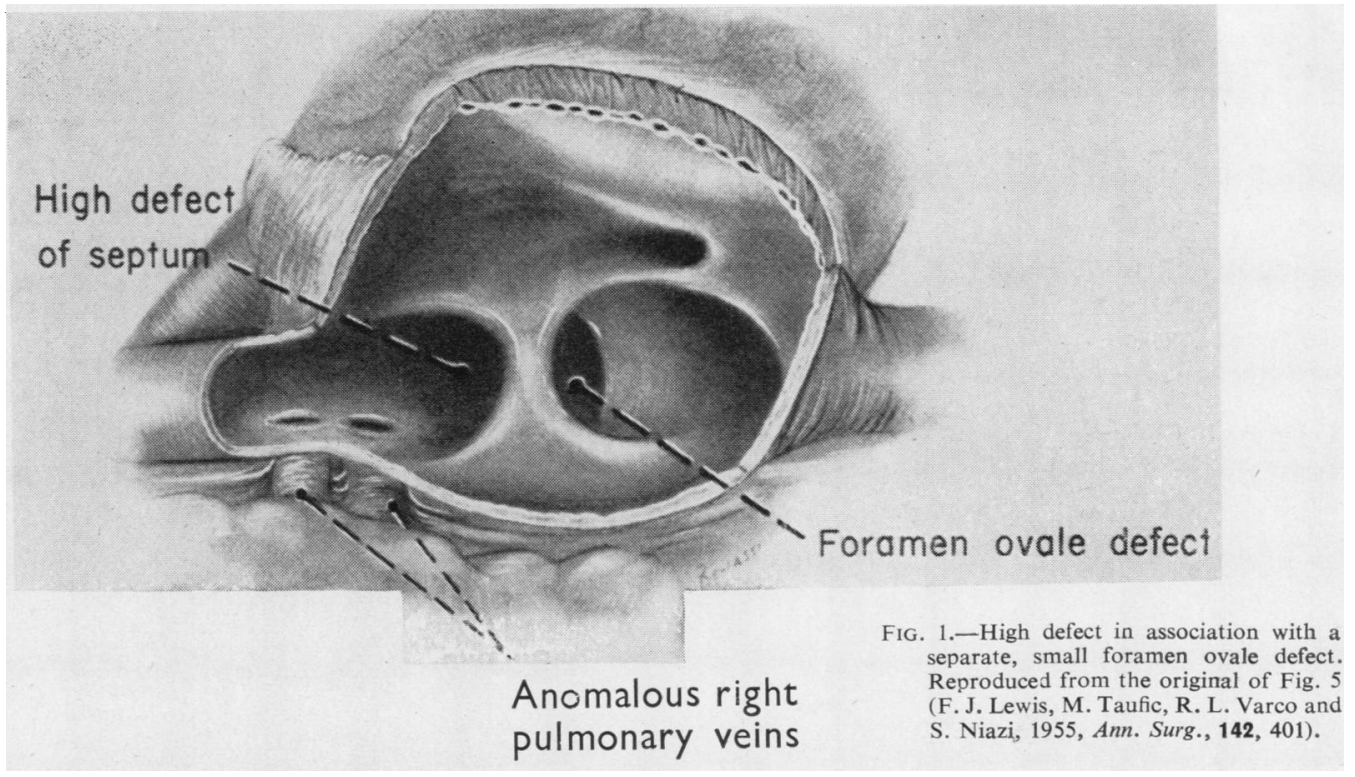

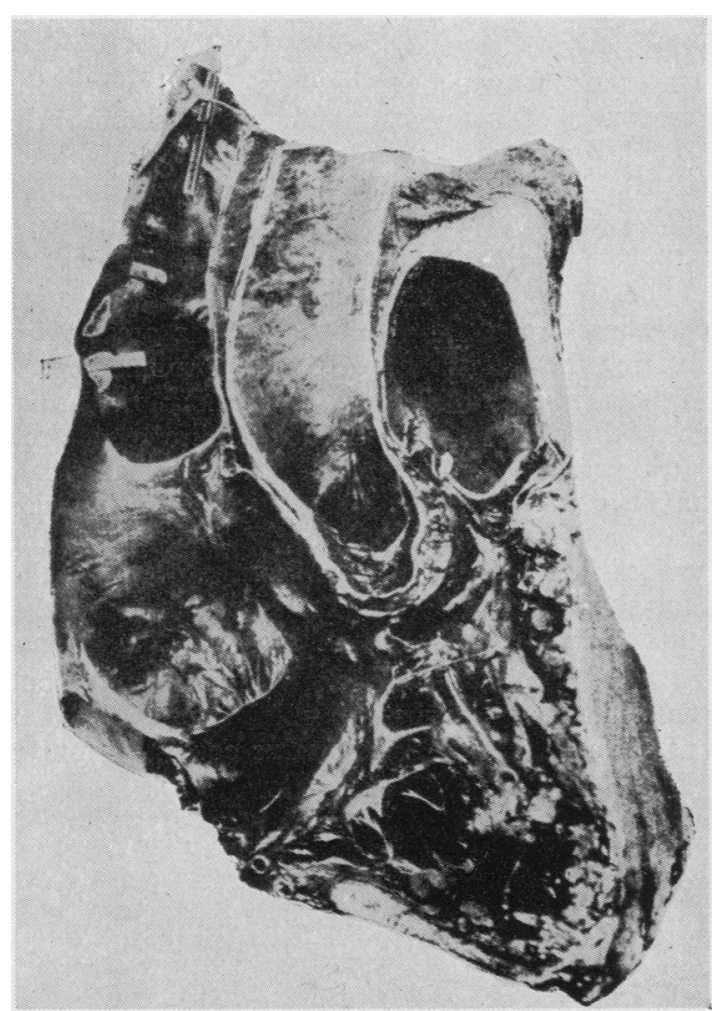

FIG. 2.-Photograph to show the heart and great vessels of a case in which four right pulmonary veins open into the superior vena cava which in turn opens equally into the right and left auricles. The crescentic upper margin of the interauricular septum is seen stretching across the mouth of the superior vena cava. Reproduced from original of Fig. 1 (A. C. Geddes 1912, Anat. Anz., 41, 449). at the site of the ostium secundum, and suggest that the components of the atrial septum in this region are not properly attached, but they do not explain how this occurs. Hudson (1955) quotes Keith (1948) as stating that it is highly probable that in the human the vestibule of the left atrium is a leftward extension of the sinus venosus, as in amphibians, and Keith himself quotes $H$ is as believing this to be the case. Hudson (1955), assuming this to be so, suggests that if some pulmonary veins were to open into the main sinus, and the rest into its leftward extension, and if the two portions of the sinus venosus were to remain in communication with each other, then an interatrial septal defect would occur and be associated with an anomaly of the pulmonary veins. No details are given as to how this might come about ; furthermore, there is no good evidence that the vestibule of the left atrium in man is derived from the sinus venosus. Hudson's description suggests to the reader that the postulated leftward extension of the sinus venosus is a tubular one, for he says that if it maintains its communication with the main sinus an interatrial defect will occur. But this cannot be so, for if the sinus venosus does extend to the left it is merely a spread of the sinus tissue into the posterior wall of the left atrium. To quote Keith (1948) “. . . the sinus area will be seen to extend into the posterior wall of the left auricle" (Fig. 3, after Keith). There is no question of any tubular extension, the persistence of which could produce an interatrial foramen. Ross (1956), also quoting Keith (1948), states that there is an extension of the sinus venosus laterally 


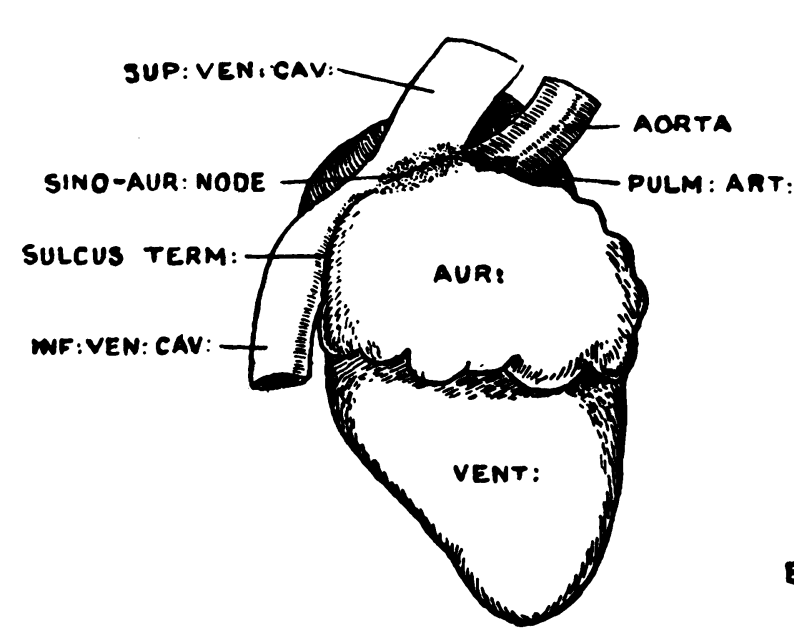

(a)

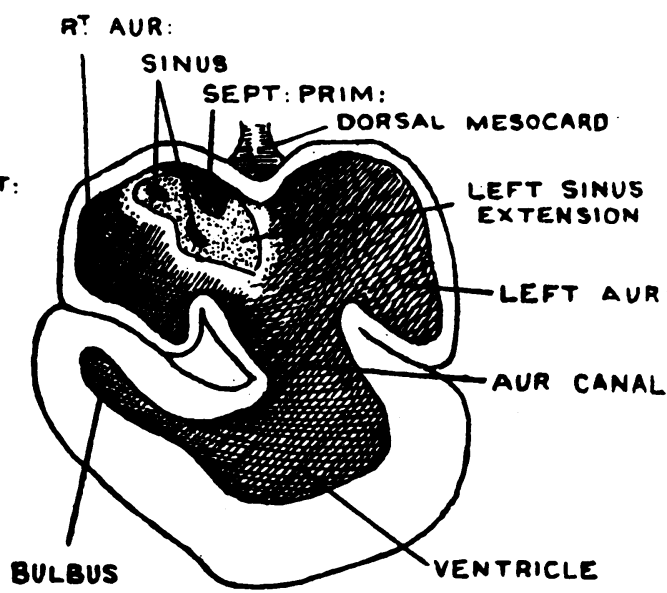

(b)

Fig. 3.-Reproduced from originals of Figs. 396 and 397 (Sir Arthur Keith, 1948, Human Embryology and Morphology, 6th ed., p. 449, Edward Arnold, London).

behind the left atrium, forming the vestibule of the sinus venosus, into which the pulmonary veins drain. He goes on to say:

"The sinus venosus and its vestibule are separated by the atrial septum, but where the absorption of the sinus venosus into the atrium is incomplete there will be a persistent communication with the vestibule adjacent to the mouths of the superior vena cava and pulmonary veins. The proximity of the orifices of these veins can account for the frequency of associated anomalous drainage."

Fig. 4, after Ross, indicates his view of how this defect occurs. This account does not provide a satisfactory explanation as to why the interatrial septum does not form properly at this site, for what is implied by this theory is simply that the posterior wall of the heart at the site of septum formation is formed by the sinus venosus, and not by the atrium proper, but, as this is postulated to be the normal state of affairs, why should it cause a failure in septal formation? Ross (1948) postulates that absorption of the sinus venosus into the right atrium is incomplete, but an examination of three hearts with this anomaly and of the various illustrations of the high defect which have been published does not support this theory. The orifices of the superior and inferior venae cavae and of the coronary sinus are always in their normal relationships, indicating that absorption of the sinus venosus is complete.

In order to understand how the defect under consideration arises, it is necessary to be familiar with certain aspects of the development of the sinus venosus, the atria, and the pulmonary vein.
The account which follows is based upon the researches of many embryologists, including His (1886), Born (1888 and 1889), Tandler (1912), Mall (1912), Frazer (1916), Davis (1927), Walmsley (1929), Odgers (1938), Keith (1948), Patten (1953), Streeter (1948), Schnitker (1952), and Licata (1954).

The sinus venosus begins as a thin-walled chamber formed by confluence of the great veins entering the caudal end of a simple tubular heart, formed initially by the fusion of paired primordia. After three weeks of intra-uterine life the paired cardiopericardial plates and endocardial heart tubes fuse to form a simple, unpaired, tubular heart, and the paired pericardial portions of the coelom fuse to form a single pericardial cavity, the ventral mesocardium breaking down immediately, but the dorsal mesocardium persisting for a time. $\subseteq$

At $3 \frac{1}{2}$ weeks of age atrioventricular, bulbo- $\frac{D}{0}$ ventricular and sino-atrial sulci appear, in that order, and demarcate the bulbus cordis, primitive $\mathcal{N}$

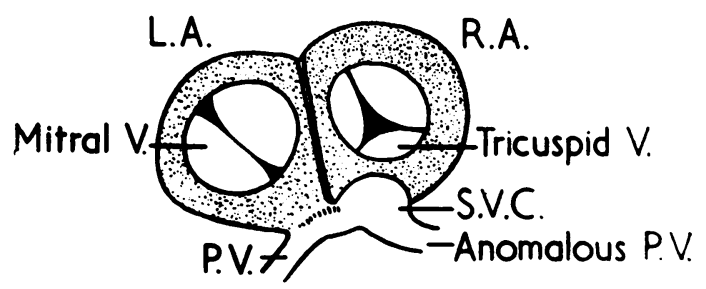

Fig. 4.-Diagram illustrating Ross's view of persistence of the $\overparen{\mathbb{D}}$ vestibule of the sinus venosus, with an anomalous pulmonary vein entering the superior vena cava. Reproduced from original of Fig. 4 (D. N. Ross, 1956, Guy's Hosp. Rep., 105, 376). 


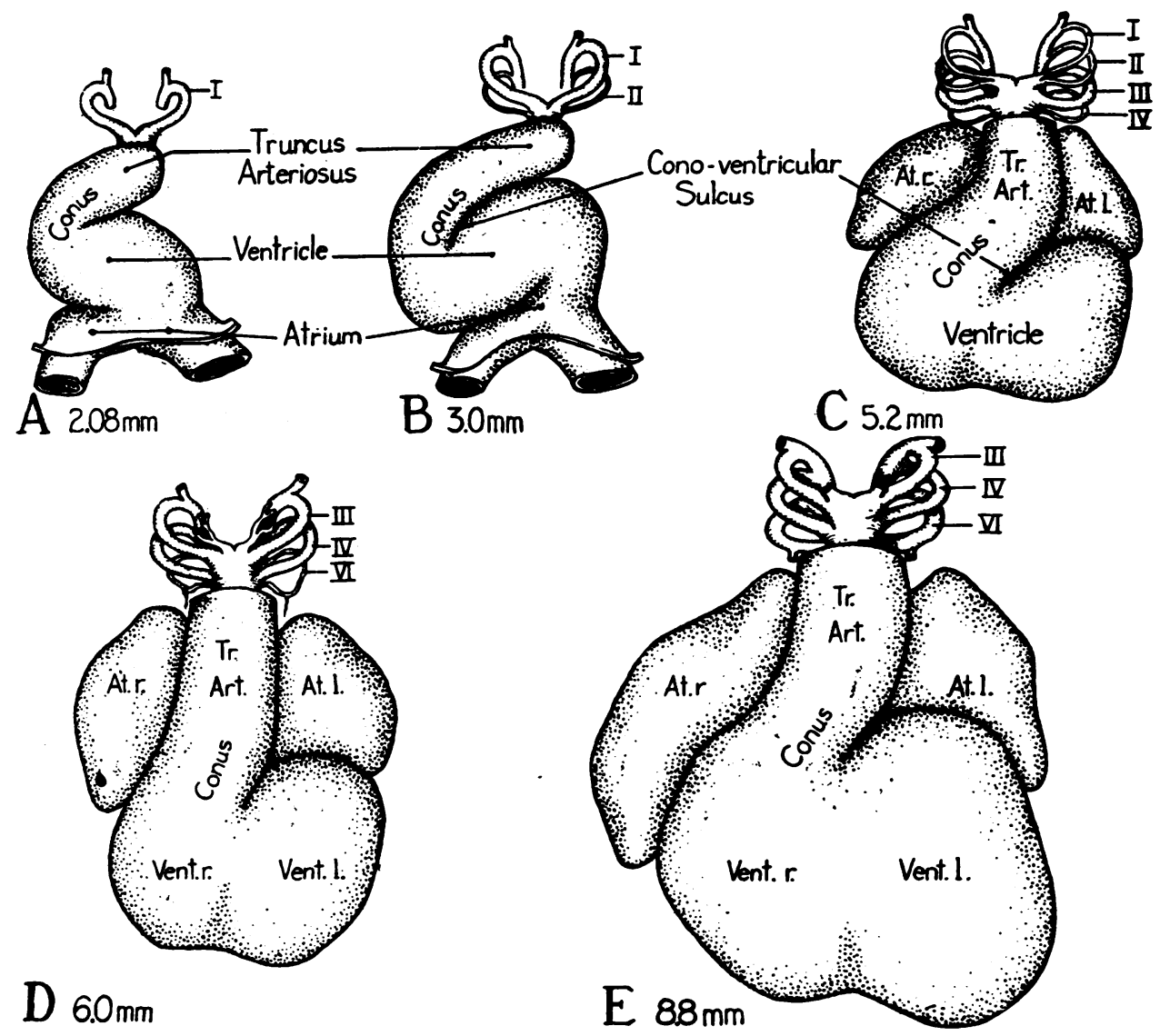

FIG. 5.-Ventral views of reconstructions of the hearts of young embryos showing the shift in the position of the truncus toward the mid-line and the reduction of the cono-ventricular sulcus. Slight modifications in the redrawing have been made in order to bring the various models into comparable orientation. A, 2.08-mm. embryo $\times 42$ (modified from Davis, 1927, Fig. 23). B, 3-mm. embryo $\times 42$ (modified from Tandler, 1912, Fig. 374). C, 5-2-mm. embryo $\times 42$ (modified from Tandler, 1912, Fig. 378). D, 6.0-mm. embryo $\times 21$ (modified from Waterston, 1918, Fig. 2). E, 8.8-mm. embryo $\times 21$ (original figure from reconstruction of EH. 35, University of Michigan Coll.). Reproduced from original of Fig. 1 (T. C. Kramer, 1942, Amer. J. Anat., 71, 343).

ventricle, primitive atrium, and sinus venosus (Figs. 5, 6, and 7). At this age the heart has developed its characteristic S-shaped bend. Fusion of the paired heart tubes occurs cephalo-caudally, so that the sinus venosus is the last chamber to be differentiated. When first formed the sinus venosus opens into the dorsicaudal part of the common atrium in the mid-line, but almost at once the sinoatrial orifice is shifted to the right, because the crescentic sino-atrial fold soon becomes deeper on the left side than on the right side. At this stage the sinus venosus receives the common cardinal veins (ducts of Cuvier) at its right and left extremities, and the paired omphalomesenteric and umbilical veins caudally (Figs. 7 and 8 ), the omphalomesenteric veins approximating closely to each other as they enter the sinus venosus. At $3 \frac{1}{2}$ weeks, therefore, the sinus venosus receives on each side the systemic, placental, and vitelline blood by separate paired veins. At 4 weeks of age the sinus venosus is well defined, its orifice is already shifted to the right, and is guarded by right and left venous valves, and it receives the same veins as described above.

Between the fourth and fifth weeks the sinus venosus is pulled cranially by the growth of the atrium, and it develops right and left horns. The right side of the sinus venosus is already larger than the left side because some of the umbilical blood is diverted from left to right. A single pulmonary vein, " the common pulmonary vein," can already be identified opening into the dorsal aspect 

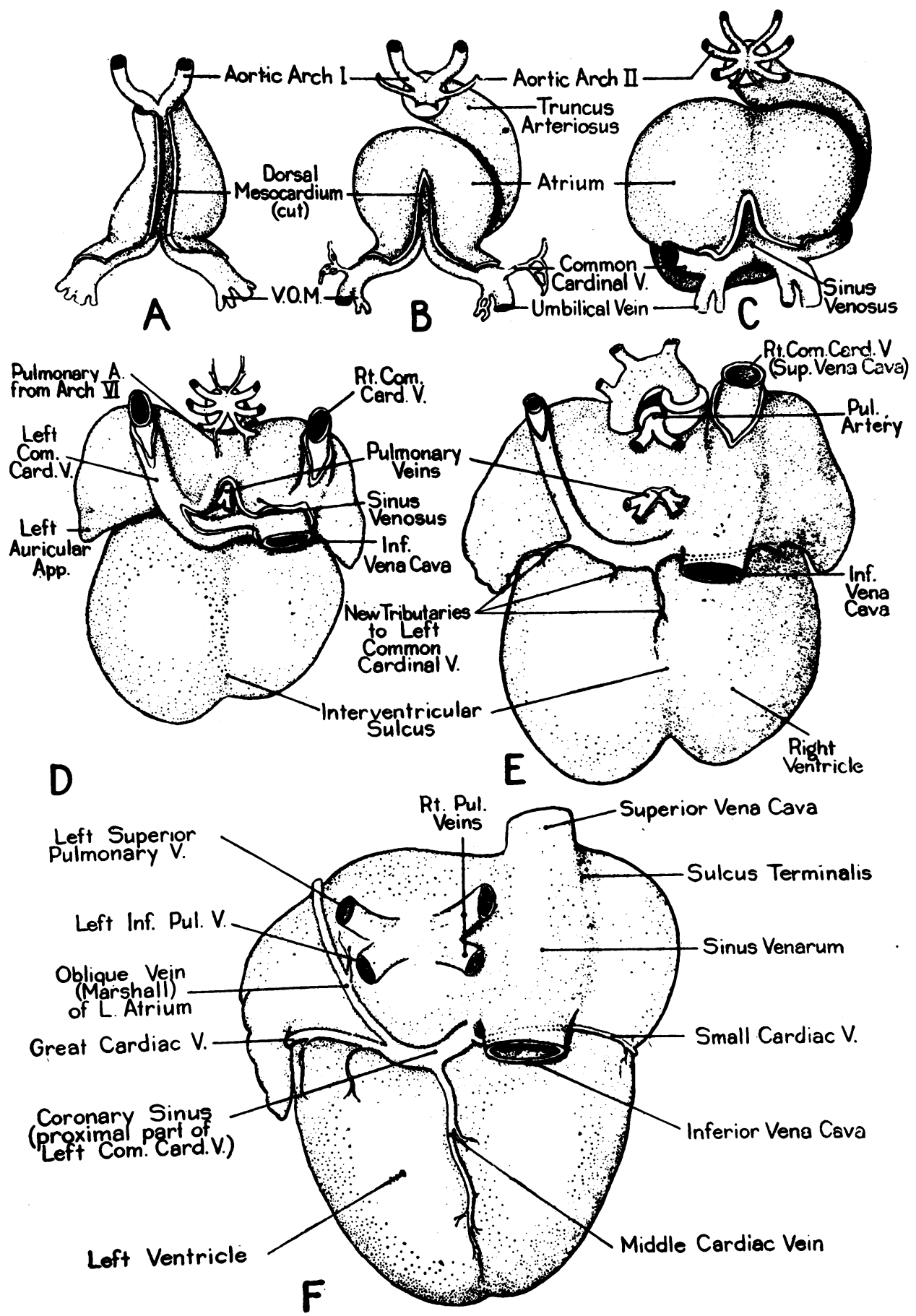

FIG. 6.-Six stages in development of the heart, drawn in dorsal aspect to show changing relations of sinus venosus and great veins entering heart. (Adapted from several sources.) A, Two and ono-half weeks (8-10 somites). B, Three weeks (12-14 somites). C, Three and one-half weeks (17-19 somites). D, Five weeks (6-8 mm., C-R.). E, Eighth week (embryos about $25 \mathrm{~mm}$.). F, 11 weeks (embryos of about $60 \mathrm{~mm}$.). Reproduced from original of Fig. 417 (B. M. Patten, 1953, Human Embryology, p. 659, The Blakiston Co., New York). 
Fig. 7.-Diagram of the heart tube showing the S-shaped bend, the primitive chambers, and the mode of entry of the common cardinal, umbilical and omphalomesenteric veins into the sinus venosus. Reproduced from original of Fig. 11 (T. Walmsley, 1929, Quain's Elements of Anatomy, 11th ed., The Heart, Vol. 4, Pt. 3, p. 16, Longmans Green, London).

Fig. 8.-Diagrams showing development of the hepatic portal circulation from the omphalomesenteric veins, and changes by which blood returning from placenta by way of umbilical veins is rerouted through liver. A, Based on conditions in pig embryos of 3-4 $\mathrm{mm}$. applicable to human embryos of fourth week. B, Based on pig embryos of about $6 \mathrm{~mm}$. applicable to human embryos of fifth week. C, Based on pig embryos of 8-9 $\mathrm{mm}$. applicable to human embryos early in sixth week. $D$, Based on pig embryos of $20 \mathrm{~mm}$. and above applicable to human embryos of seven weeks and older. Reproduced from original of Fig. 406 (B. M. Patten, 1953, Human Embryology, p. 645, The Blakiston Co., New York.

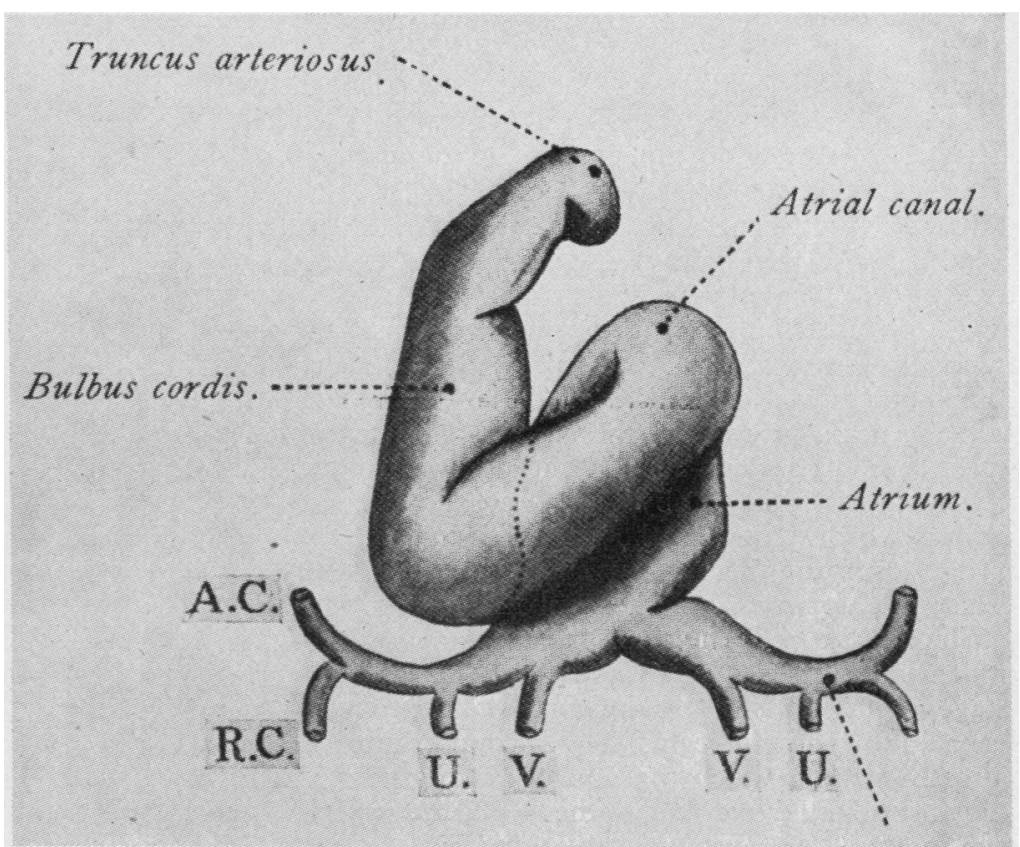

Fra. 7
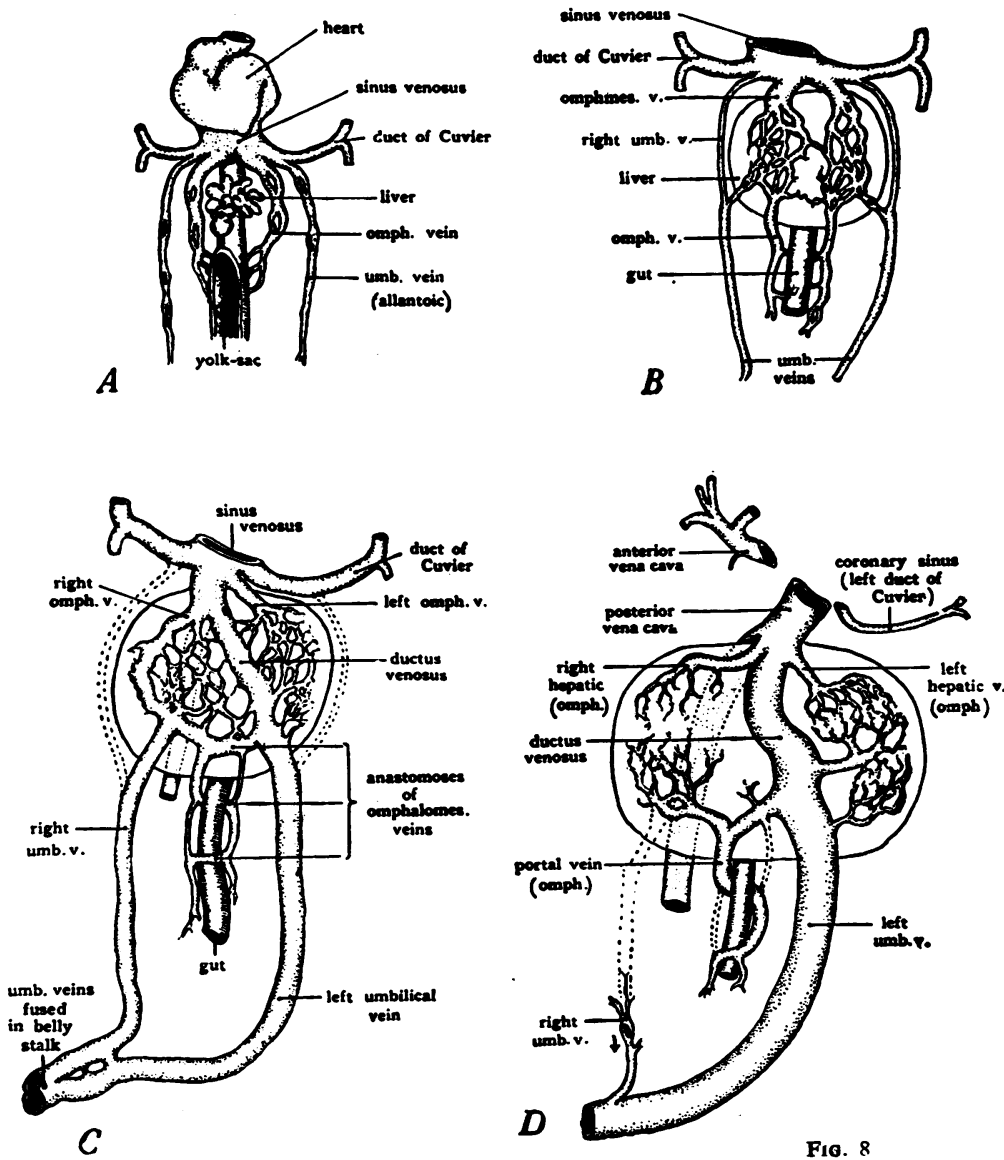

Fio. 8 
of the left atrium, as shown by Fig. 9 (after Streeter, 1948). I do not propose to discuss the vexed question of whether this vein originally communicates with the atrium or with the sinus venosus. At this and subsequent stages it certainly enters the left atrium.

At 5 weeks of age the sinus venosus still receives the common cardinal, umbilical, and omphalomesenteric veins, but the latter are already being invaded by the growing columns of liver cells. The sino-atrial orifice is well to the right and is guarded by right and left venous valves which unite at the cephalic end of the orifice to form the septum spurium (Fig. 10A). This runs forwards on the cephalic wall of the atrium. The right horn of the sinus venosus is much larger than the left horn (Fig. 6). At this stage partitioning of the atrium, atrioventricular canal, and ventricle begins. The septum primum is already identifiable on the dorsicephalic aspect of the atrium in the mid-line, to the left of the septum spurium and left venous valve, and just to the right of the orifice of the common pulmonary vein. The area between the septum primum and the left

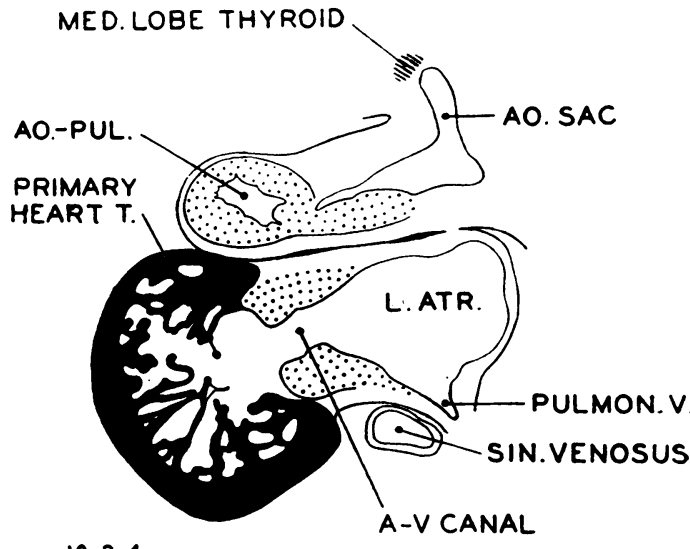

$10 \cdot 2 \cdot 4$

FIG. 9--Section through heart of the human embryo between 30 and 32 days of age showing the common pulmonary vein opening into the left atrium. Reproduced from original of Fig. 2 (G. L. Streeter, 1948, Contr. Embryol. Carneg. Instn, 32, 133).

venous valve is called the interseptovalvular space. A large ostium primum is present, and the dorsal and ventral atrioventricular endocardial cushions are approaching each other (Fig. 11 A and B).

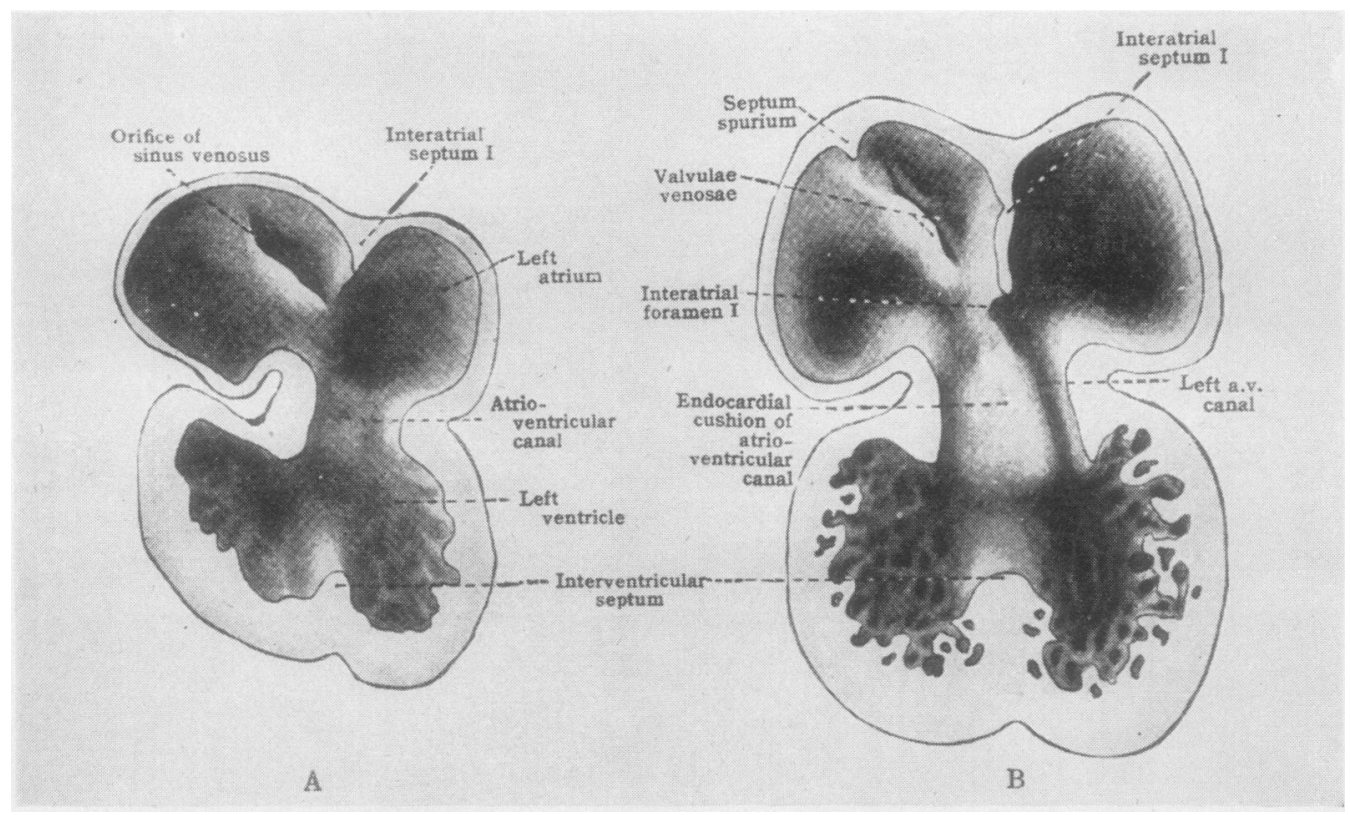

FIG. 10.- Semischematic drawings of interior of the heart to show initial steps in its partitioning. A, Cardiac septa are represented at stage reached in human embryos early in fifth week of development. Note especially the primary relations of interatrial septum primum. Based on original reconstructions of the heart of a $3 \cdot 7-\mathrm{mm}$. pig embryo and on Tandler's reconstructions of corresponding stages of the human heart. B, Cardiac septa as they appear in human embryos of sixth week. Note restriction of interatrial foramen primum by growth of interatrial septum primum. Based on original reconstructions of the heart of $6-\mathrm{mm}$. pig embryo, on Born's reconstructions of rabbit heart, and on Tandler's reconstructions of corresponding stages of the human heart. Reproduced from original of Fig. 418 (B. M. Patten, 1953, Human Embryology, p. 660, The Blakiston Co., New York). 
A. 4-5 $\mathrm{mm}$.

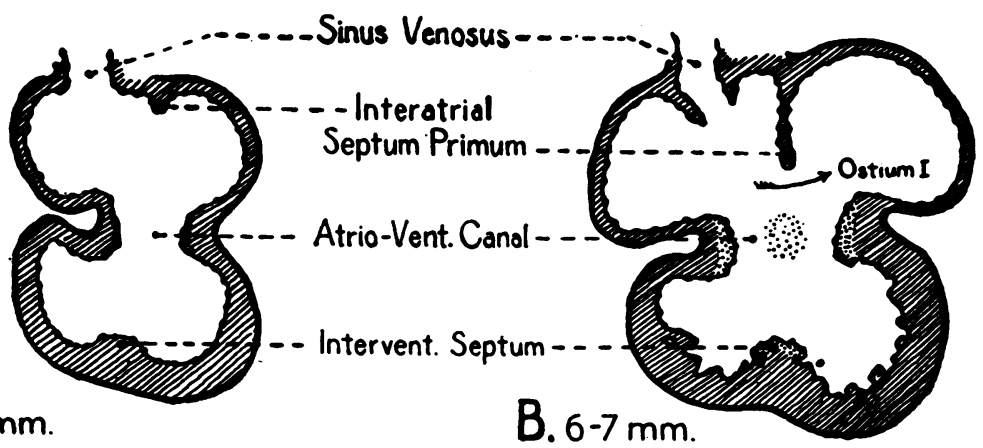

Valvulae

Venosoe.

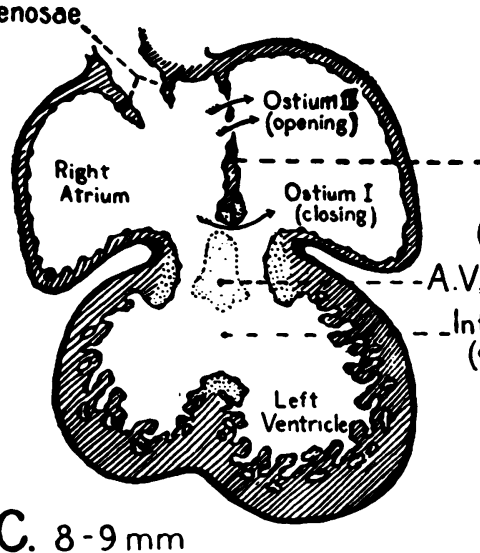

B. 6-7 mm

Septum II.

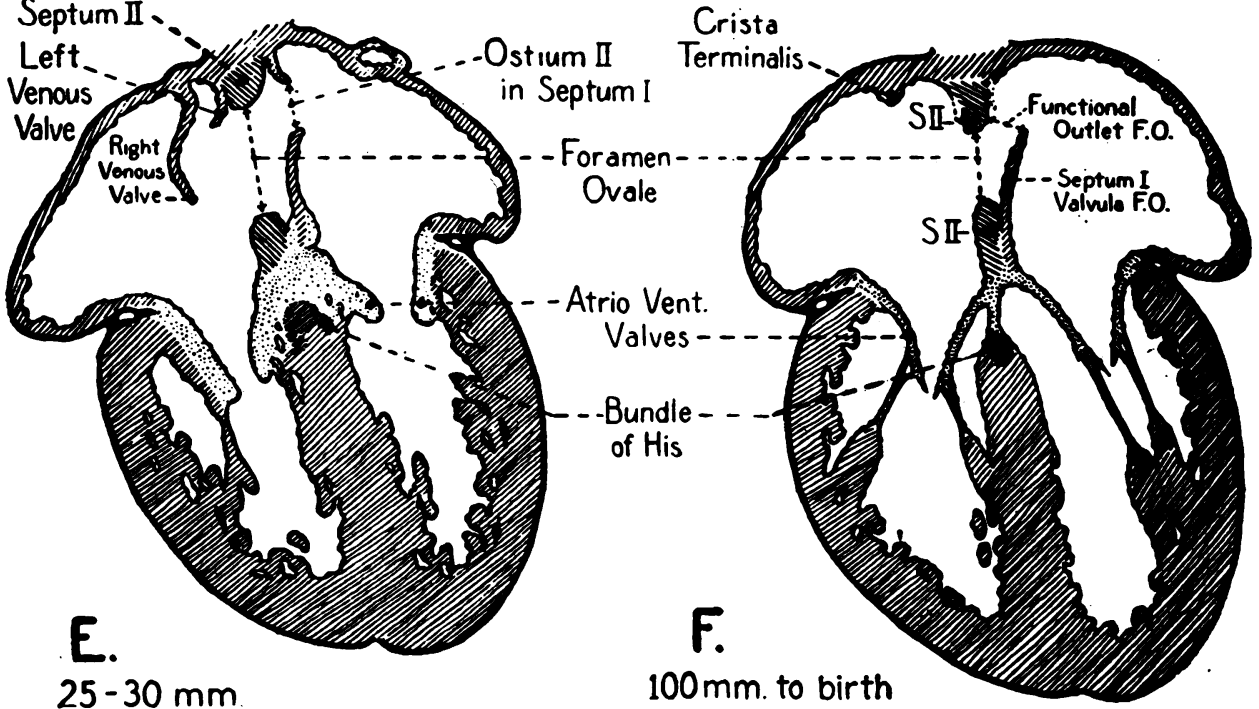

FIG. 11.-Sectional plans of embryonic heart in frontal plane showing the development of the venous valves and of the interatrial septum. Note particularly the interseptovalvular space, and the way in which the cephalodorsal limb of the septum secundum fills it completely (Fig.11 D), and carries the left venous valve and the septum primum into the cavity of the atrium on its right and left aspects (Fig. 11E). Reproduced from original of Fig. 422 (B. M. Patten. 1953, Human Embryology, p. 665, The Blakiston Co., New York). 

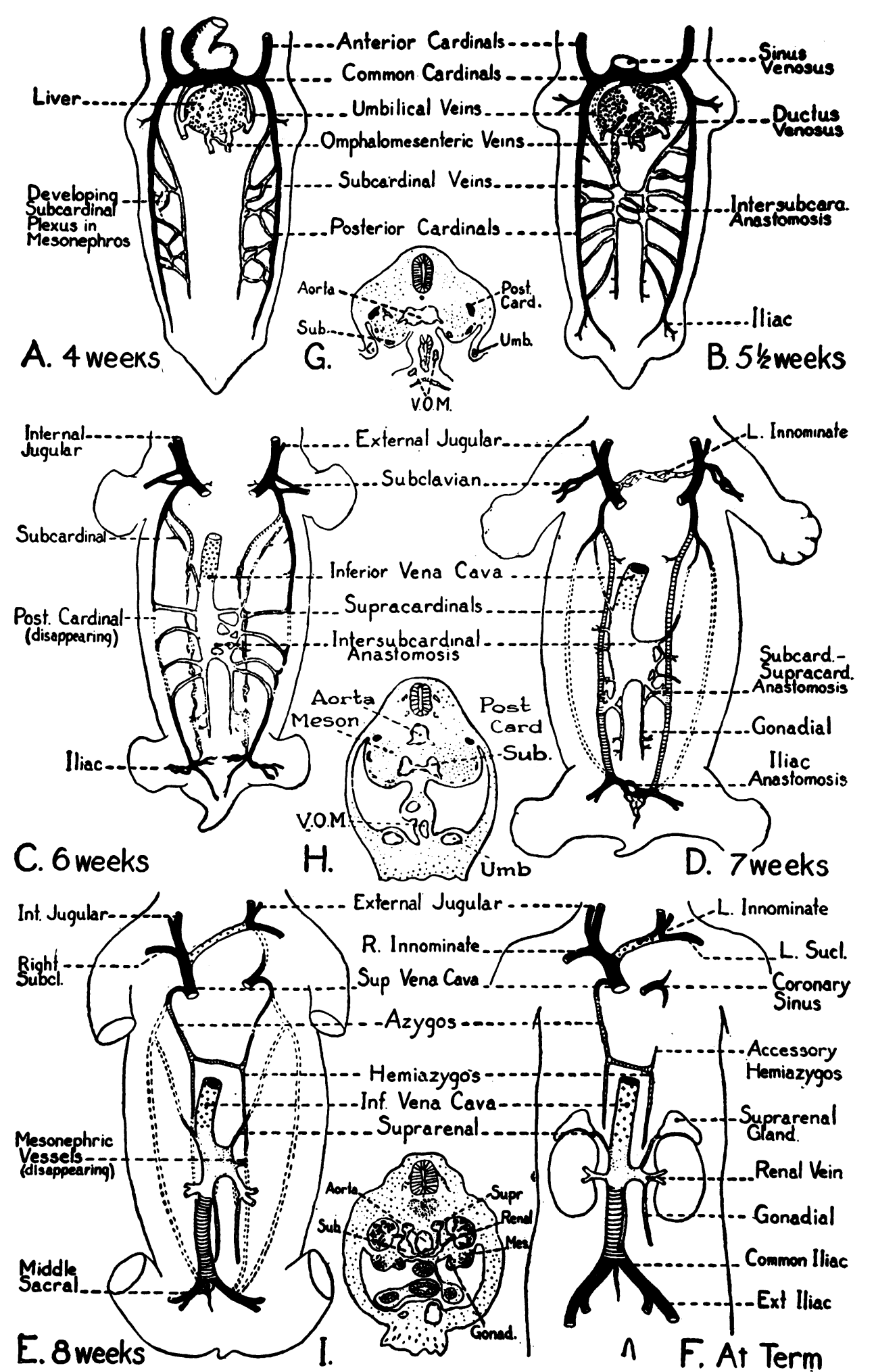

Fig. 12. - Schematic ventral view diagrams showing some of the steps in the development of inferior vena cava. (Based)on the work of McClure and Butler.) Cardinal veins are shown in black, subcardinal system is stippled, supracardinalsjare horizontally hatched, and vessels arising independently of these three systems are indicated by small crosses. Reproduced ifrom original of \Fig. 403 ?(B. M. Patten, 1953, Human Embryology, p. 639, The Blakiston Co., New York). 
At 6 weeks the sinus venosus begins to be incorporated into the right atrium, a process which is completed between the sixth and eighth weeks. The liver has invaded the omphalomesenteric and umbilical veins (Fig. 8C) ; the latter have lost their connexion with the sinus venosus, and the ductus venosus and intrahepatic portion of the inferior vena cava are formed, so that the sinus venosus now receives the two common cardinal veins and the inferior vena cava, formed by the termination of the right omphalomesenteric vein (Fig. 6D), and has assumed a crescentic shape. The deviation from left to right of placental and omphalomesenteric blood, together with the blood from the lower parts of the body (Fig. 12), associated with the formation of the ductus venosus and the intrahepatic portion of the inferior vena cava, results in a marked preponderance of the right horn of the sinus venosus. At this stage (Figs. 10B and 11D) the atrioventricular endocardial cushions are fused, the septum primum fuses with these cushions to close the ostium primum, the ostium secundum is present, and the septum secundum begins to appear as a crescentic ridge on the ventricephalic portion of the atrium, facing the opening of the sinus venosus.

In the seventh week of intra-uterine development the preponderance of the right horn of the sinus venosus is further enhanced by the development of the left innominate vein from the small thymicothyroid veins, as this diverts blood from the left anterior cardinal area to the right horn of the sinus venosus (Fig. 12D). Thereafter the left common cardinal vein and the left horn of the sinus venosus regress, the latter forming the coronary sinus (Fig. $12 \mathrm{E}$ and $\mathrm{F}$ ). Absorption of the right horn and transverse portion of the sinus venosus into the right atrium is well advanced, so that the superior vena cava (derived from the right anterior and common cardinal veins), the inferior vena cava, and the coronary sinus now open by separate orifices into the sinus venarum of the right atrium (Figs. 6E, 8D, and 13). As the sinus venosus is taken into the right atrium the superior vena cava is drawn into the cephalic wall of the atrium while the inferior vena cava is drawn into its caudal wall (Figs. 6E and F, and Fig. 13). Originally the two common cardinal veins opened into the lateral extremities of the sinus venosus, i.e., into the right and left horns, while the omphalomesenteric veins opened close together into the caudal margin of its transverse portion (Fig. 7 and Fig. 8A and B); in other words the omphalomesenteric veins opened between the two common cardinal veins. The terminal part of the inferior vena cava represents the terminal portion of the right omphalomesen- teric vein, reinforced by the ductus venosus, and by an anastomotic vessel connecting it with the right subcardinal vein just above the subcardinal sinus (Fig. 8C and D). The inferior vena caval orifice would be expected, therefore, to lie between the orifices of the superior vena cava and the coronary sinus, and somewhat caudal to them. But as the above changes are occurring the heart is migrating caudally so that traction is applied on the two anterior cardinal veins, and through them to the common cardinal veins. As a result the ducts of Cuvier, which are transversely placed at 4 weeks of age, become oblique at 5 weeks, when they run caudally, as well as ventrimedially, to reach the sinus venosus from the body wall (Figs. 6 and 14). This causes the horns of the sinus venosus to be pulled headwards, and is responsible for the crescentic shape of the sinus venosus referred to above. During the seventh week the left innominate vein develops and the left anterior cardinal vein caudal to it then regresses (Fig. 12D to F). The headward traction on the right common cardinal vein continues, while that on the left side is probably relieved. This is no doubt why, as the sinus venosus is absorbed into the right atrium, the orifice of the superior vena cava comes to be situated at the junction of the dorsal and cephalic walls of the atrium, whereas the orifice of the coronary sinus remains more caudally located, being placed to the left of the orifice of the inferior vena cava, these two orifices maintaining their original relationship (Fig. 13). This reorientation of the locations of the openings into the right atrium is important to the production of the type of interatrial septal defect which is the subject of consideration in this paper.

At this stage (7 weeks) the right and left venous valves and septum spurium are well developed, and the septum secundum is larger. The latter has developed cephalodorsal and ventricaudal limbs which embrace a crescentic free border, facing the orifice of the inferior vena cava and forming the margins of the foramen ovale (Fig. 15). The cephalodorsal limb occupies the whole of the interseptovalvular space, and carries the left venous valve and the septum primum inwards on its right and left aspects (Fig. 11E). The septum secundum is still by no means fully developed, so that the foramen ovale, circumscribed by its free edge, is still large, and a considerable portion of the ostium secundum in the septum primum remains uncovered. This still leaves a large interatrial communication within the confines of both the foramen ovale in the septum secundum and ostium secundum in the septum primum. 


$$
\frac{96}{90}
$$


FIG. 15.-Dextral view of heart of $31.5 \mathrm{~mm}$. embryo with the right atrium opened and the right venous valve removed. (Reconstruction $\times 100$, illustration $\times 35$.) Reproduced from original of Fig. 7 (R. H. Licata, 1954, Amer. J. Anat., 94, 73).

Fig. 16.-Dextral view of heart of $25 \mathrm{~mm}$. embryo with atrium opened. A tag of tissue which is attached to the septum primum is just visible above the right venous valve. (Reconstruction $\times 100$, illustration $\times 40$. $) ~ R e-$ produced from original of Fig. 4 (R. H. Licata, 1954, Amer. J. Anat., 94, 73).

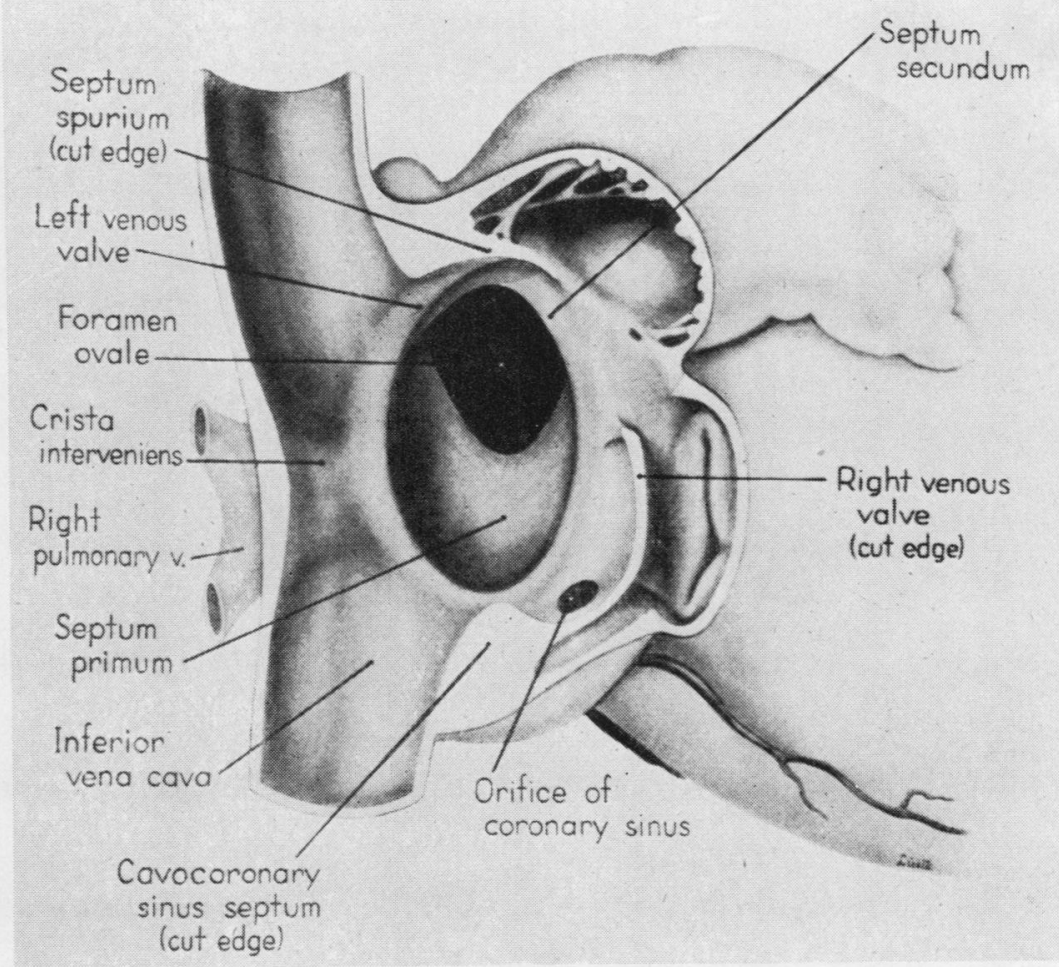

FiG. 15

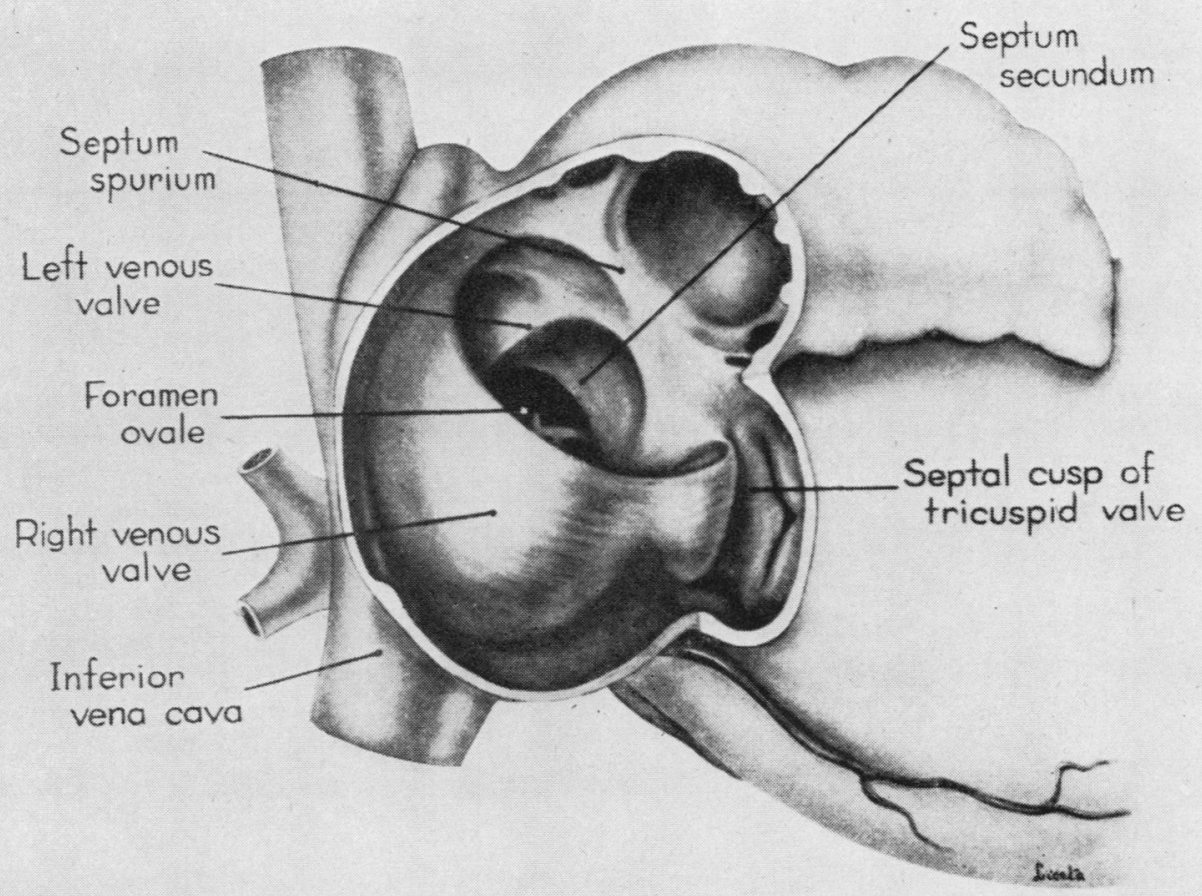

Fio. 16 


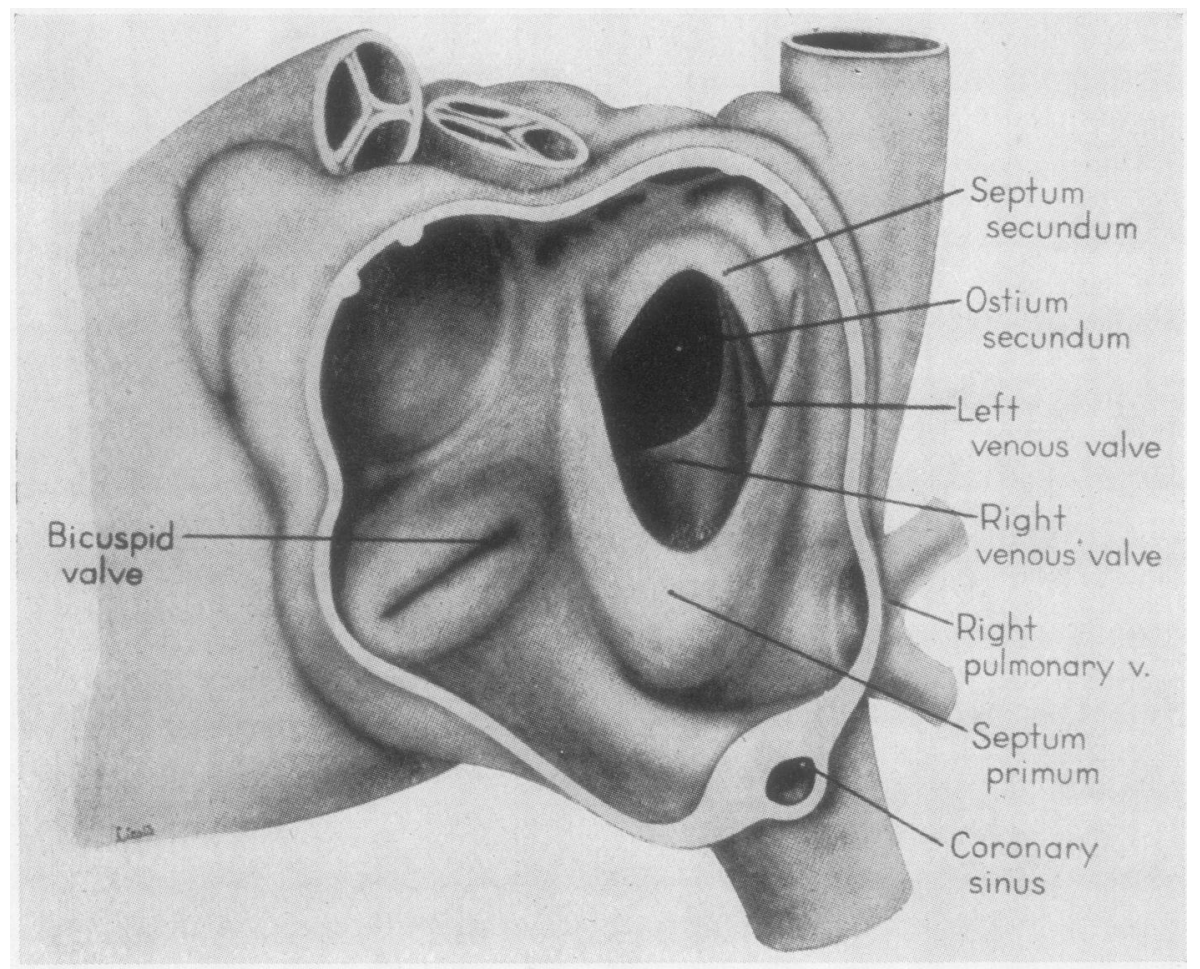

Fig. 17.-Heart of a $31.5 \mathrm{~mm}$. embryo with the left atrium opened to show the interatrial septal complex in sinistral view and the close proximity of the opening of the common pulmonary vein to the septum primum. Reproduced from original of Fig. 9 (R. H. Licata, 1954, Amer. J. Anat., 94, 73).

At 8 weeks of age the sinus venosus is completely absorbed into the right atrium to form the sinus venarum, which receives the superior and inferior venae cavae and the coronary sinus, as described above. The right venous valve is large and well developed (Fig. 16), but the left venous valve and septum spurium are probably already regressing. By the ninth week, as shown by Licata (1954) this process is well advanced, and the left venous valve is fusing with the septum secundum (Figs. 15 and 16). At this stage the septum secundum is well developed, but the foramen ovale is still large and the interatrial communication of considerable size. According to Patten (1953), the common pulmonary vein has been absorbed into the left atrium, which now receives right and left pulmonary veins from the two lungs. The orifice of the right pulmonary vein is very close to the septum primum (Fig. 17). By the eleventh week the right and left pulmonary veins have been taken into the left atrium which then contains four pulmonary orifices.

By the time the embryo is 8 weeks old, therefore, the sinus venosus has been completely incorporated into the right atrium to form the sinus venarum, the right and left atria have been separated, though a functional foramen ovale persists, the right atrium receives the superior and inferior venae cavae and the coronary sinus in their final positions, and the left atrium receives two or four pulmonary veins, of which the right open very close to the septum primum. There is no need to follow development to a further stage.

Some of the essential points in the embryology may be summarized with benefit. The sinus venosus becomes defined at $3 \frac{1}{2}$ weeks, and by $4 \stackrel{\text {. }}{=}$. weeks the sino-atrial junction has already shifted $\tilde{O}$ to the right. Between the fourth and fifth weeks the sinus venosus is dragged cranially by the 0 atrium and has developed right and left horns ; its $\omega$ right side is already larger than its left side. A common pulmonary vein can be seen entering the left atrium. At 5 weeks septation of the atrium $\overparen{D}$ begins. At 6 weeks the sinus venosus begins to be? incorporated in the right atrium, a process which 0 is complete by the eighth week. At 6 weeks also the ostium secundum appears, the septum secundum begins to develop, and the intrahepatic $\mathscr{Q}$ portion of the inferior vena cava is formed by reorganization of the venous drainage from the 


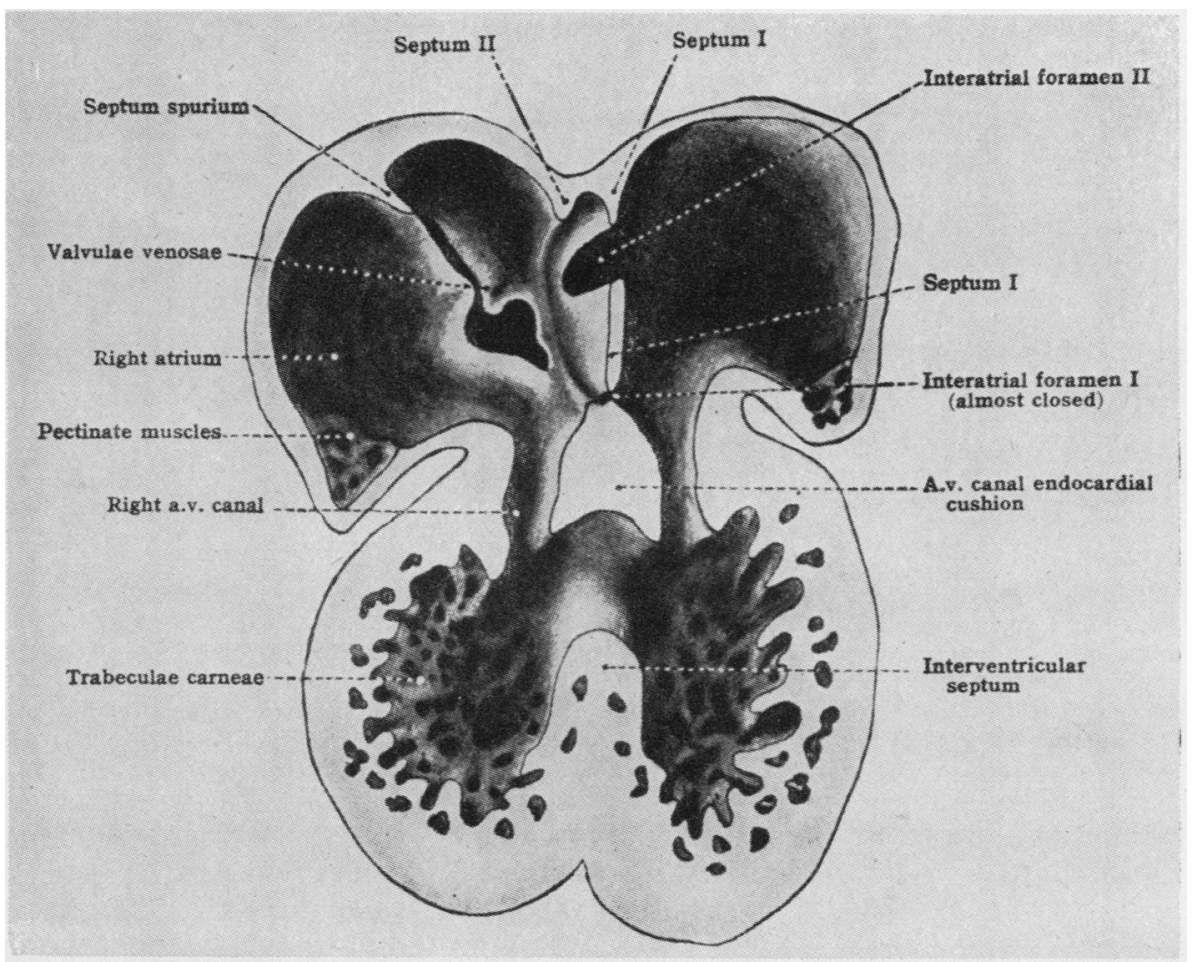

FIG. 18.- Semischematic drawing of interior of the heart to show start of the interatrial septum secundum and appearance of interatrial foramen secundum in the septum primum. Based on original reconstructions of the heart of a 9.4-mm. pig embryo and on Tandler's reconstructions of the heart of human embryos of the seventh week. Reproduced from original of Fig. 420 (B. M. Patten, 1953, Human Embryology, p. 662, The Blakiston Co., New York).

placenta, the yolk sac, and gut, and the lower part of the body. I believe this to be a crucial age with regard to the production of high defects of the interatrial septum. At 7 weeks incorporation of the sinus venosus into the right atrium is far advanced, the superior and inferior venae cavae have been drawn into the cephalic and caudal ends of the dorsal wall of the right atrium, and their orifices, together with that of the coronary sinus, occupy their final positions. At 8 weeks both absorption of the sinus venosus into the right atrium, and separation of the two atria, are complete, and the common pulmonary vein has been taken into the left atrium.

We are now in a position to determine how the sinus venosus type of interatrial communication comes about. At the sixth week of intra-uterine life the stage is set for this abnormality to occur. If development has been normal the septum primum will have been absorbed in its dorsicephalic portion to form the ostium secundum. To the right of the septum primum and ostium secundum, and separated from the septum primum by the inter- septovalvular space (Fig. 10 and Fig. 11B and C), are the septum spurium and the left venous valve, the latter bounding the left margin of the sinoatrial orifice. As already indicated, the septum secundum develops at this age in the ventricephalic part of the atrium, to the right of the septum primum, and its cephalodorsal limb comes to occupy the entire width of the interseptovalvular space (Figs. 18, 13, and $11 \mathrm{D}$ and $\mathrm{E}$ ), so that it carries into the cavity of the atrium the left venous valve on its right aspect and the septum primum on its left aspect. The septum primum is a thin membraneous partition consisting of two layers of endocardium, separated by subendocardial tissue, but the septum secundum is a thick structure, formed by an inflexion of the musculature of the atrial wall (Fig. 11E). It is for this reason that the cephalodorsal limb of the septum secundum is enabled to fill the whole of the interseptovalvular space. During its subsequent growth this limb of the septum covers progressively the ostium secundum, while its ventricaudal limb fuses with the septum intermedium, produced by the union 


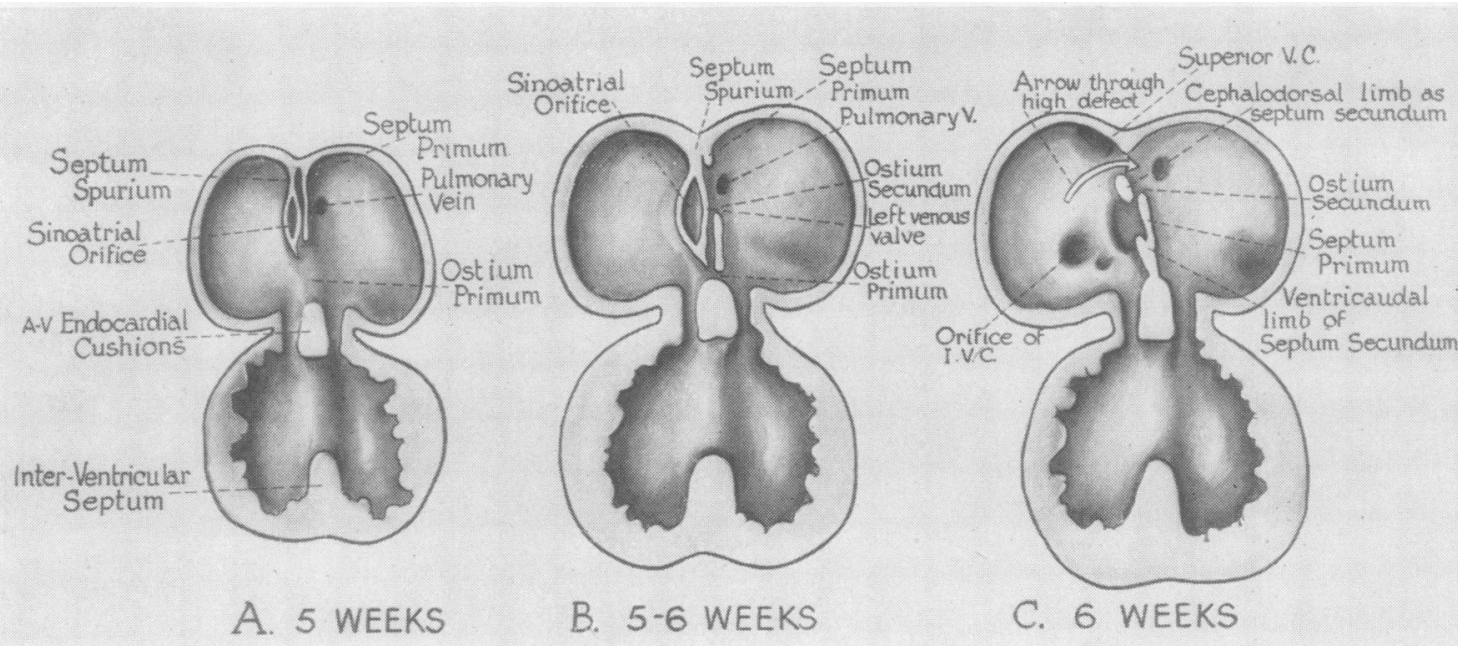

FIG. 19.-Schematic drawings to illustrate the author's view of how the high, or sinus venosus, type of interatrial septal defect is produced.

of the ventral and dorsal atrioventricular endocardial cushions. The free margin of the septum secundum delimits the foramen ovale.

As pointed out by Lewis et al. (1955), the sinus venosus type of interatrial defect lies at the site of origin of the ostium secundum, before it moves ventrally, and is situated above the fossa ovalis. In my view the fundamental error in development, which leads to the production of this anomaly, is that the sino-atrial orifice is not shifted as far to the right as it normally is. If this shift were deficient the septum primum would develop immediately to the left of the sino-atrial orifice in contact with the left venous valve. This would mean that there could be no interseptovalvular space (Fig. 19). Regression of the left venous valve would accompany degeneration of the dorsicephalic portion of the septum primum to form the ostium secundum, and this would leave the latter in line with the left margin of the cephalic portion of the sino-atrial orifice. When the cephalodorsal limb of the septum secundum developed it would find, instead of the atrial wall flooring the interseptovalvular space, the cephalic portion of the sino-atrial orifice. It is obvious that at this site the musculature of the atrial wall could not inflect, so that a gap in the attachment of the cephalodorsal limb of the septum secundum to the atrial wall would occur at the site of the cephalic part of the sino-atrial orifice.

As the septum secundum develops the sinus venosus is taken into the right atrium, and, as described above, the superior vena cava comes to open into the junction of the dorsal and cephalic walls of the atrium, while the inferior vena cava opens into the junction of its dorsal and caudal walls. As this happens the orifice of the superior vena cava comes to lie opposite to the ostium secundum and to that portion of the septum secundum which has failed to gain attachment to the wall of the atrium. A situation would then arise in which an interatrial communication would be present which would face the orifice of the superior vena cava, would be in line with the left (medial) margin of this orifice, and would have no superior margin. The ventral, caudal, and dorsal margins of this communication would be formed by the peripheral margin of that portion of the cephalodorsal limb of the septum secundum which had failed to gain attachment to the atrial wall, because it developed in the line of the sino-atrial orifice. Furthermore the abnormal communication would lie above the foramen ovale, and would be separated from it by the depth of the cephalodorsal limb of the septum secundum. Because the unattached portion of the latter would lie opposite the ostium secundum an interatrial communication would be inevitable (Fig. 1).

The explanation given above indicates the correctness of the suggestions of Lewis et al. $N$ (1955) that the defect occurs at the site of the $\mathbb{\omega}$ ostium secundum, and that the components of the atrial septum in this region do not become pro- 0 perly attached. It also explains satisfactorily all $\stackrel{\varnothing}{\overparen{D}}$ the anatomical characteristics of high atrial septal $\stackrel{\mathscr{\rho}}{+}$ defects described by Lewis et al., and the descrip- $T$ tion given by Ross (1956) of the defect reported by him as ". . . lying within the orifice of the superior vena cava in its medial wall. . .."

The only fact which remains to be elucidated is that high defects are associated with anomalous drainage of the right superior, and sometimes of 
the right middle or inferior, pulmonary vein into the superior vena cava. It was pointed out above that, between the fourth and fifth weeks of intrauterine life, a common pulmonary vein can be identified opening through the dorsal wall of the left atrium close to the mid-line (Fig. 6D and Fig. 9). After the development of the septum primum, in the fifth week, the orifice of this vein lies very close to the septum on its left side. Should the abnormal conditions postulated above occur, the left margin of the misplaced sino-atrial orifice would be very close to the orifice of the common pulmonary vein (Fig. 19), and after the formation of the ostium secundum no septum would separate the two. As the sinus venosus became absorbed into the right atrium, so that the superior vena cava came to open into the dorsicephalic portion of the sinus venarum, and the common pulmonary vein became incorporated into the left atrium, it would be easy for one of the right branches of the vein to be drawn into the superior vena cava at its junction with the right horn of the sinus venosus. The right and left branches of the common pulmonary vein diverge towards their respective sides (Fig. 6F) so that the right pulmonary vein and its tributaries would become closely approximated to the terminal portion of the superior vena cava, and no septum would intervene between them as they opened into the heart. The superior and inferior divisions of the original right pulmonary vein diverge cranially and caudally. As the right pulmonary vein is taken into the atrium it is obvious that its cranial branch, which becomes the right superior pulmonary vein, would be the one most likely to establish an entry into the superior vena cava, which itself opens into the cranial end of the dorsal wall of the right atrium. This explains why it is that anomalous pulmonary venous drainage affects the right lung, and usually its superior vein.

\section{SUMMARY}

1. An account of the development of the sinus venosus is given, and the relationships of this to septation of the atrium and to the development of the pulmonary vein are described.

2 . The fundamental error leading to the production of a high defect of the interatrial septum is held to be a failure of the sino-atrial orifice to shift as far to the right as it should do. This leads to the septum primum developing in immediate proximity to the left margin of the sino-atrial orifice, to failure of the intersepto-valvular space to develop, and to development of the septum secundum in line with the left portion of the sinoatrial orifice. As a result the cephalodorsal limb of the septum secundum cannot form by inflexion of the atrial wall where it is interrupted by the cephalic portion of the sino-atrial orifice so that a gap in the attachment of the septum secundum occurs at this site. Because this gap lies opposite to the ostium secundum an interatrial communication occurs. This communication ultimately faces the superior vena cava, and it lies above the foramen ovale, from which it is separated by the cephalodorsal limb of the septum secundum.

3. The associated anomalous pulmonary venous drainage is easily explained by the proximity of the misplaced sino-atrial orifice to the orifice of the common pulmonary vein, and by the fact that no septum intervenes between these two, because of the error in atrial septation described above. The configuration of the common pulmonary vein and its tributaries is such that the anomalous vein is usually the right superior one.

4. This theory does not invoke a leftward extension of the sinus venosus into the left atrium.

5. There is no evidence that defective absorption of the sinus venosus into the right atrium plays any part in the production of high interatrial communications.

My thanks are due to all authors and publishers who have kindly allowed me to utilize the figures from their works, and to my colleagues, Professor J. S. Baxter and Dr. L. R. West, for their helpful suggestions.

I should also like to thank Miss June Williams, who drew Fig. 19, and Mr. R. Marshall for the photographs.

REFEPENCES

Bedford, D. E., Sellors, T. H., Somerville, W., Belcher, J. R., and Besterman, E. M. M. (1957). Lancet, 1, 1255.

Born, G. (1888). Anat. Anz., 3, 606.

Brandenburg, R. O., and DuShane, J. W. (1956). Proc. Mayo Clin., 31, 509.

Cooley, J. C., and Kirklin, J. W. (1956). Ibid., 31, 523.

Davis, C. L. (1927). Contr. Embryol. Carneg. Instn, 19, 245.

Frazer, J. E. (1916). J. Anat. (Lond.), 51, 19.

Geddes, A. C. (1912). Anat. Anz., 41, 449.

His, W. (1886). Beiträge zur Anatomie des Menschlichen Herzens, Vogel, Leipzig.

Hudson, R. (1955). Brit. Heart J., 17, 489.

Ingalls, N. W. (1907). Anat. Rec., 1, 14.

Keith, Sir Arthur (1948). Human Embryology and Morphology, 6th ed., p. 451. Edward Arnold, London.

Kramer, T. C. (1942). Amer. J. Anat., 71, 343.

Lewis, F. J., Taufic, M., Varco, R. L., and Niazi, S. (1955). Ann. Surg., 142, 401 .

Licata, R.' H. (1954). Amer. J. Anat., 94, 73.

Mall, F. P. (1912). Ibid., 13, 249.

Odgers, P. N. B. (1938).' J. Anat. (Lond.), 72, 247

Patten, B. M. (1953). Human Embryology, 2nd ed., p. 659, etc. Blakiston, New York.

Rogers, H. M., and Edwards, J. E. (1948). Amer. Heart J., 36, 28.

Ross, D. N. (1956). Guy's Hosp. Rep., 105, 376.

Schnitker, M. A. (1952). Congenital Anomalies of the Heart and Great

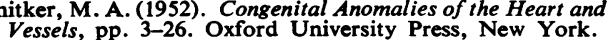

Streeter, G. L. (1948). Contr. Embryol. Carneg. Instn, 32, 133.

Tandler, J. (1912). In Manual of Human Embryology, ed by Keibel, F., and Mall, F. P., Vol. 2, pp. 534-570. Lippincott, Philadelphia.

Toscano-Barbosa, Ė., Brandenburg, R. O., and Burchell, H. B. (1956). Proc. Mayo Clin., 31, 513.

Wagstaffe, W. W. (1868). Trans. path. Soc. Lond., 19, 96.

Wakai, C.S., and Edwards, J. E. (1956). Proc. Mayo Clin., 31, 487.

Swan, H. J. C., and Wood, E. H. (1956). Ibid., 31, 500.

Walmsley, T. (1929). Quain's Elements of Anatomy, 11th ed., The Heart, Vol. 4, Pt. 3. Longmans Green, London.

Watkins, E., and Gross, R. E. (1955). J. thorac. Surg., 30, 469. 